\title{
Surgical oophorectomy or GnRH plus tamoxifen adjuvant therapy for breast cancer in low-risk premenopausal women: comparative benefits and risks
}

\begin{abstract}
Background: While the combination of ovarian suppression or ablation treatment and tamoxifen or an aromatase inhibitor has been demonstrated to provide better outcomes as adjuvant therapies in premenopausal women with hormone receptor positive breast cancer, than treatment with tamoxifen alone, the details of applying these results in clinical practice, and the risks and benefits of the different ovarian treatments, particularly in women at lower risk for disease recurrence and death, have received limited attention.
\end{abstract}

Methods: Details of clinical trials investigating combination hormonal adjuvant therapies, particularly with tamoxifen, were reviewed focusing on issues pertinent to assessment of risks and benefits in clinical practice.

Results: Equivalent survival outcomes from surgical oophorectomy (SO) or GnRH agonist treatment plus tamoxifen, for which there are the most data at present, make the major decision issues for individual patients in choosing between these treatments: interest in future pregnancy, availability of data on secondary biological effects, capacity to adhere to a GnRH injection program for 5years, and ability to optimize dental hygiene (for taking bisphosphonate additional treatment). Other considerations applicable in individual patients include comparative secondary treatment effects, financial costs, and psychological impacts.

Conclusion: If a patient with low-risk for recurrence breast cancer has interest in a future pregnancy, GnRH treatment is clearly appropriate. Otherwise, all major and minor risks of GnRH treatment are greater than those for SO treatment, when combined hormonal treatment with tamoxifen is taken.

Keywords: adjuvant therapy, surgical oophorectomy, GnRH, tamoxifen, risks, benefits
Volume II Issue 4 - 2020

Richard R Love

Department of Computer Science, Marquette University, USA

Correspondence: Richard R Love, MD, Department of Computer Science, Marquette University, Milwaukee, WI 2708 Columbia Road, Madison, WI 53705, USA, Tel 608-698-788I, Fax 608 238-788I, Email richardibcrf@gmail.com

Received: July 24, 2020 | Published: August I2, 2020

\section{Introduction}

Combined hormonal therapy has now been defined as providing optimal disease-free (DFS) and overall survival (OS) benefits, in low- risk-for-recurrence premenopausal patients with hormone receptor positive breast cancer. ${ }^{1}$ Ovarian suppression or ablation plus tamoxifen, is currently the best-defined optimal choice; ovarian treatment plus an aromatase inhibitor is still under evaluation, with increased DFS benefits, but uncertainty about OS benefits compared with ovarian treatment plus tamoxifen. Application however, of these results in clinical practice, particularly for lower-risk patients, is strongly debated., ${ }^{2,3}$ Current NCCN guidelines call for a "balanced discussion of the risks and benefits of ovarian suppression therapy", without providing relevant information or specifying what the important issues are. ${ }^{3}$ The focus of this communication is to offer such a framework and details.

\section{Methods}

The details of three major studies which provide information allowing estimation of absolute additional treatment benefits of ovarian suppression or ablation plus tamoxifen over tamoxifen treatment alone are reviewed. Practical considerations important for clinical application of these potential benefits in individual patients are defined, specifically identifying differences between surgical oophorectomy and GnRH treatments.

\section{Results}

There are 3 specific trials which address absolute disease-free and overall survival benefits of combined hormonal treatment (with ovarian suppression or ablation) versus tamoxifen alone for lowrisk for recurrence (mostly of luminal A subtype meaning estrogen receptor positive, progesterone receptor positive, Her-2/neu oncogene overexpression negative) patients (Table 1).$^{1,4,5}$ In all 3 trials patients had confirmed pathological diagnoses of operable breast cancer, had to be premenopausal by history or recent menstrual periods, had to have not received any systemic treatment prior to randomization, and by history and physical examination and chest $\mathrm{X}$ ray and liver function tests, to have no signs of metastatic disease. The positive hormonal receptor status of patients varied some in the 3 trials; in the ECOG and SOFT trials patients could have only one hormonal receptor positive, while in the Vietnam trial data presented the patients had positive receptors for both proteins. The biggest differences among the trial populations shown in Table 2, concern lymph nodal status and chemotherapy treatments. In the ECOG and Vietnam trial 
populations, all patients were axillary node negative and none received chemotherapy. In the SOFT trial, approximately $20 \%$ of patients were axillary node positive, and $55 \%$ had chemotherapy also. The data would suggest that combined treatment gives DFS benefits at 5 and 8 years of approximately 2 and $4 \%$ respectively, and OS benefits of $2 \%$ (Table 1). These magnitudes of absolute benefits are of sizes that have been the bases for recommendation of one adjuvant treatment over another in other circumstances.

Table I Survival outcomes from SO or GnRH+ tamoxifen in 3 trials

\begin{tabular}{llll}
\hline $\mathbf{N}$ & Treatment & \multicolumn{2}{c}{ 5-year OS and DFS } \\
\hline E3193 (4) 345 & Tamoxifen & $95.20 \%$ & $87.90 \%$ \\
$\mathrm{~N}-\mathrm{T}=<3 \mathrm{~cm}$ & vs & NS & NS
\end{tabular}

$\mathrm{ER}+\mathrm{PR}+: 88 \%$

Tam+LHRH (36\%)
or Tam+SO* (42\%)
or Tam+RO** (13\%)
or Tam alone (9\%)

8-year OS and DFS

\begin{tabular}{|c|c|c|c|}
\hline SOFT (I) 3047 & Tamoxifen & $91.50 \%$ & $78.90 \%$ \\
\hline $\begin{array}{l}\text { No previous } \\
\text { chemo: }\end{array}$ & vs & & \\
\hline \multirow[t]{5}{*}{1356} & $\begin{array}{l}\text { Tam +ovarian } \\
\text { suppression } \\
\text { or Tam +ovarian } \\
\text { suppression }\end{array}$ & $93.30 \%$ & $83.20 \%$ \\
\hline & $\square \mathrm{SO} *$ or RO** & \multirow{4}{*}{$92.10 \%$} & \multirow{4}{*}{$85.90 \%$} \\
\hline & vs & & \\
\hline & $\begin{array}{l}\text { Exemestane + ovarian } \\
\text { suppression } \\
\text { or exemestane + ovarian } \\
\text { suppression }\end{array}$ & & \\
\hline & $\square$ so* or RO** & & \\
\hline
\end{tabular}

5-year DFS and OS

Vietnam (5) $162 \quad$ SO+Tamoxifen $\quad 94.40 \% \quad 88.50 \%$

$\mathrm{N}-, \mathrm{ER}+, \mathrm{PR}+$

Her-

*SO, surgical oophorectomy

**RO, radiation oophorectomy

That specifically surgical oophorectomy plus tamoxifen is of major benefit has been convincing shown in results from two trials, and the outcomes are clearly comparable to those seen in the other two listed trials in Table 1 (Figure 1).,

While a meta-analysis of ovarian ablation/suppression alone in early breast cancer has not confirmed outcome benefits [DFS 0.72 (0.49-1.04) OS 0.82 (0.47-1.43)], the specific study results in Table 1 are supported by the trends in this meta-analysis. ${ }^{7}$

Outcomes with surgical oophorectomy vary by timing of this surgery according to menstrual cycle phase with clear benefit demonstrated in patients in progesterone test confirmed follicular or luteal phases. ${ }^{6,8,9}$
In contrast $\mathrm{GnRH}$ data are from multiple different treatments. In SOFT, $19 \%$ of patients treated with GnRH stopped this treatment without undergoing subsequent ovarian ablation. Other patients did stop $\mathrm{GnRH}$ at various times before 5years of treatment and underwent either surgical oophorectomy or radiation ovarian ablation. 19\% of patients treated with ovarian targeting therapies stopped their tamoxifen treatment. ${ }^{1}$ Additionally, suppression of estradiol levels in individual patients is submaximal, with a wide range of estradiol values. ${ }^{10}$ In sum, unlike the situation with surgical oophorectomy where the biological impact in individual patients is very clear, with $\mathrm{GnRH}$ treatments this is significantly variable, unpredictable and not monitorable. ${ }^{10}$

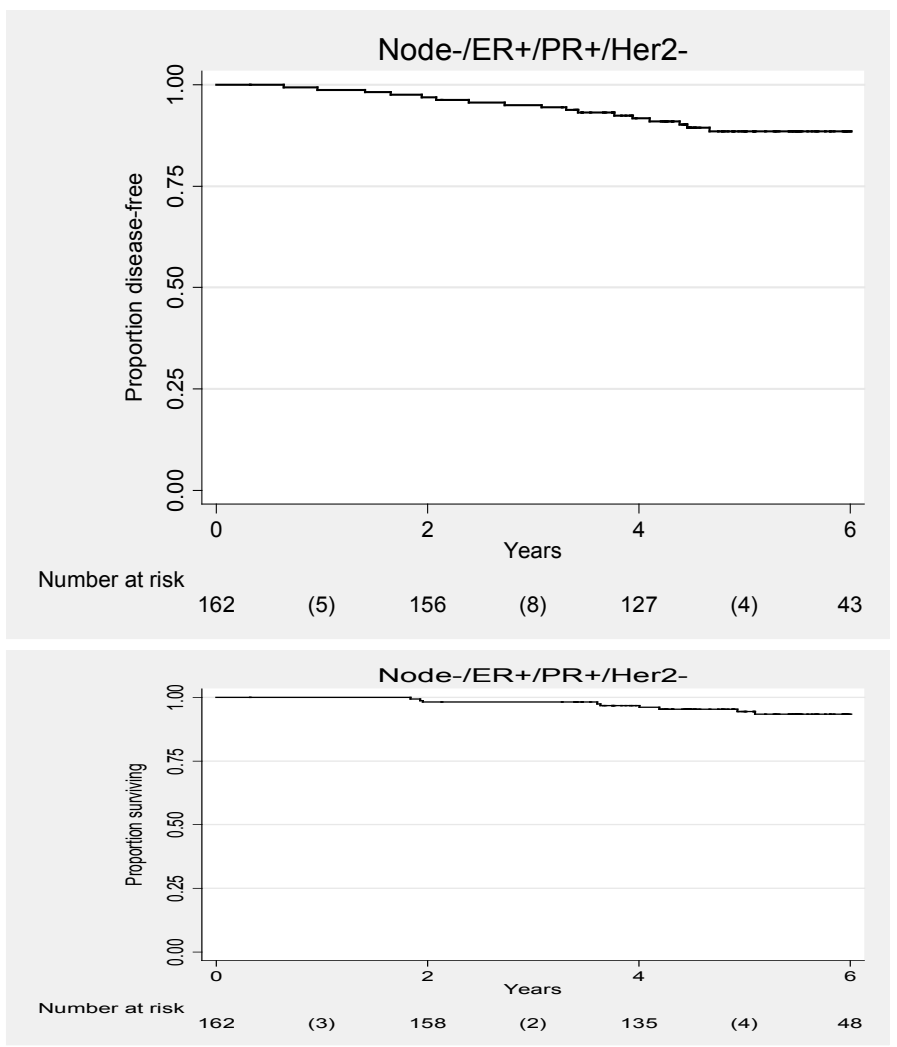

Figure I Disease-Free (top) and overall survival (bottom) in 162 node negative luminal $A$ patients treated with surgical oophorectomy plus tamoxifen $x$ 5years (6)

Beyond consideration of absolute DFS and OS benefits, the major clinical issues in choosing between $\mathrm{SO}$ and $\mathrm{GnRH}$ ovarian treatments are suggested in Table 2. Clearly, interest in a future pregnancy indicates that for the immediate decision, GnRH treatment should be favored. As has been discussed, there are specific uncertain immediate effects of GnRH treatments, but additionally there are limited data about the myriad of significant secondary effects of such hormonal treatments with tamoxifen, in contrast to the circumstances with SO plus tamoxifen, where the long-term effects on mortality overall, cardiovascular, and other organ systems are well-understood, and importantly, on balance, very favorable numerically. ${ }^{11}$ In particular, $\mathrm{SO}+\mathrm{T}$ has minimal, limited adverse effects on bone mineral density, while GnRH treatments with tamoxifen are clearly associated with bone loss, which mandate consideration of specific bisphosphonate treatments with attendant costs and risks. ${ }^{12-14}$ There are no independent data about the effects of bisphosphonates as anti-cancer agents in 
premenopausal women. The discussions about safety of SO alone simply do not apply to SO plus tamoxifen. ${ }^{1}$ Finally, for most women needing treatment globally, GnRH monthly injections are impractical, and as a consequence associated with increasing non-adherence over time, and loss of outcomes benefits. ${ }^{15}$

Table 2 Factors favoring SO or GnRH plus tamoxifen

\begin{tabular}{|c|c|c|}
\hline & Favors SO & Favors GnRH \\
\hline Possible future pregnancy & & +++ \\
\hline $\begin{array}{l}\text { Completeness of information on } \\
\text { biological effects } 1,10,11\end{array}$ & +++ & \\
\hline Secondary biological effects ${ }^{\prime \prime}$ & ++++ & \\
\hline Inability to optimize dentalhygiene ${ }^{14}$ & +++ & \\
\hline $\begin{array}{l}\text { Inability/high inconvenience } \\
\text { bisphosphonate treatment }\end{array}$ & +++ & \\
\hline $\begin{array}{l}\text { Inability/high inconvenience monthly } \\
\mathrm{GnRH} \text { injections }\end{array}$ & ++++ & \\
\hline
\end{tabular}

Three other issues are worthy of patient discussion. In the perspective of this author, the symptoms intensity issues of combined ovarian and tamoxifen treatment are overemphasized and not considered carefully in light of the specifically available data. "One must conclude that the symptomatic intermediate and long-term impacts and contribution to long-term in-adherence with ovarian plus tamoxifen treatments versus tamoxifen alone, are not large and may vary remarkably with populations". ${ }^{11}$ Secondly, the costs of monthly GnRH for most women in the world, who must pay out of pocket for such treatment, are out of reach, which situation of course compromises treatment adherence. Since SO is an inpatient treatment, in contrast this is obtainable by most women, whose hospitalization costs are covered. Finally, inadequate attention has been paid to the comparative psychological costs of $\mathrm{SO}$ versus $\mathrm{GnRH}$ treatments. SO allows the patient to get the treatment significantly "over", while monthly GnRH injections remind the patient repeatedly of her at risk status.

The use of genomic tests to better define recurrence risk status is worthy of consideration, with the proviso that the majority of singly assessed for estrogen receptor status patients (who are defined as Her2/neu negative also), will be double receptor positive and definitively luminal A subtype, who will more-than-average strongly benefit from combined ovarian targeted plus tamoxifen treatment. ${ }^{16}$

\section{Discussion}

This review of practical consideration in choosing surgical oophorectomy or $\mathrm{GnRH}$ treatments with tamoxifen for adjuvant therapy in appropriate low-risk patients makes clear that for the majority of patients SO is an optimal choice. Indeed, when given this choice (without the kinds detailed information favoring SO discussed here), a majority of patients chose surgical oophorectomy. ${ }^{4}$

\section{Acknowledgments}

None.

\section{Funding}

None.

\section{Conflicts of interest}

The author reports no conflicts of interest

\section{References}

1. Francis PA, Pagani O, Fleming GF, et al. Tailoring adjuvant endocrine therapy for premenopausal breast cancer. New Engl J Med. 2018;379:122-137.

2. Vogel SE. 8-year update of SOFT and TEXT trials: positive but not definitive. ASCO Post. 2018.

3. https://www.nccn.org/professionals/physician gls/pdf/breast.pdf.

4. Tevaarwerk AJ, Wang M, Zhaon F, et al. Phase III comparison tamoxifen versus tamoxifen plus ovarian function suppression in premenopausal women with node negative, hormone receptor positive breast cancer (E3193, INT-0142): a trial of the Eastern cooperative oncology group. $J$ Clin Oncol. 2014;32:3948-3958.

5. Love RR, Duc NB, Allred DC, et al. Oophorectomy and tamoxifen adjuvant therapy in premenopausal Vietnamese and Chinese women with operable breast cancer. J Clin Oncol. 2002;20:2559-2566.

6. Love RR, Laudico AV, Dinh NV, et al. Timing of adjuvant surgical oophorectomy in the menstrual cycle and disease-free and overall survival in premenopausal women with operable breast cancer. $J$ Natl Cancer Inst. 2015;107(3):djv064.

7. Cuzick J, Ambroisine L, Davidson N, et al. Use of luteinising-hormonereleasing hormone agonists as adjuvant treatment in premenopausal patients with hormone-receptor-positive breast cancer: a meta-analysis of individual patient data from randomised adjuvant trials. Lancet. 2007;369:1711-1723.

8. Love RR, Hossain SM, Hussain M, et al. Luteal versus follicular phase surgical oophorectomy plus tamoxifen in premenopausal women with metastatic hormone receptor positive breast cancer. Europ J Cancer. 2016;60:107-116.

9. Love RR. Low-progesterone "luteal phase" surgical oophorectomy is ineffective hormonal therapy in pre-menopausal women with hormone receptor- positive breast cancer. Clin Res Gynecol Obstet. 2017;1(1):103.

10. Dowsett M, Lonning PE, Davidson NE. Incomplete estrogen suppression with gonadotropin-releasing hormone agonists may reduce clinical efficacy in premenopausal women with early breast cancer. J Clin Oncol. 2016;34:1580-1583.

11. Love RR. Adjuvant surgical oophorectomy plus tamoxifen: new efficacy and secondary effects data. J Can Res Adv Ther. 2020;1(1):22-28.

12. Love RR, Young GS, Laudico AV, et al. Bone mineral density changes following surgical oophorectomy and tamoxifen adjuvant therapy for operable breast cancer in pre-menopausal Filipino and Vietnamese women. Cancer. 2013;119:3746-3752.

13. Editorial. Oral health: prevention is key. The Lancet. 2009.

14. Khan AA, Morrison A, Hanley DA, et al. Diagnosis and management of osteonecrosis of the jaw: a systematic review and international consensus. J Bone Miner Res. 2015;30:3-23.

15. Love RR. Surgical oophorectomy plus tamoxifen provides the optimal systemic treatment for pre-menopausal women with hormone sensitive breast cancer. J Surg. 2017.

16. Love RR. Adjuvant surgical oophorectomy plus tamoxifen in premenopausal women with operable breast cancer: a global treatment option. Clin Breast Cancer. 2016;16:233-237. 